\title{
O Protocolo de Análise Semiótica Musicoterapêutica de Canções e seu uso como instrumento de Avaliação Musicoterapêutica
}

\author{
Renato Tocantins Sampaio \\ (Universidade Federal de Minas Gerais, Belo Horizonte, Minas Gerais, Brasil) \\ renatots@musica.ufmg.br
}

\begin{abstract}
Resumo: As canções são comumente utilizadas na prática clínica musicoterapêutica com uma ampla variedade de condições de saúde e em diversos tipos de abordagem clínica. Este artigo apresenta uma proposta de análise de canções no contexto musicoterapêutico construído a partir da teoria e prática da Semiótica da Canção (Tatit). Apresenta-se um caso clínico no qual a análise semiótica musicoterapêutica de duas canções foi utilizada. Verifica-se que a análise semiótica musicoterapêutica de canções pode ser uma ferramenta útil para compreender a etapa do processo musicoterapêutico que está sendo vivenciada e, também, para indicar possíveis caminhos futuros de intervenção clínica com o paciente.

Palavras-chave: Musicoterapia; Análise Semiótica Musicoterapêutica de Canções; Avaliação Musicoterapêutica.
\end{abstract}

The Semiotic Music Therapy Song Analysis Protocol and its use as Music Therapy Assessment

Abstract: Songs are commonly used in music therapy clinical practice with a variety of health conditions and with many types of clinical approaches. This article presents a proposal for song analysis in the music therapy context built upon theory and practice of Song Semiotics (Tatit). We present a clinical case in which two semiotic music therapy song analysis were conducted is presented. The Semiotic Music Therapy Song Analysis is considered a useful tool to understand the stage of the music therapy process that is being experienced and to provide possible pathways for clinical intervention with the patient.

Keywords: Music Therapy; Semiotic Music Therapy Song Analysis; Music Therapy Assessment.

\section{A Avaliação Musicoterapêutica}

A Musicoterapia consiste em um processo sistemático de intervenção no qual o terapeuta ajuda o paciente a promover sua saúde utilizando experiências musicais no contexto de uma relação terapêutica (BRUSCIA, 2000). Na Musicoterapia, o paciente vivencia a música através de atividades de audição, recriação ${ }^{1}$, composição e improvisação musicais que são selecionadas, sugeridas e guiadas pelo musicoterapeuta em função das necessidades clínicas do paciente, levando em consideração suas habilidades já desenvolvidas, habilidades ainda não desenvolvidas (potenciais), gostos, histórico e ideias sobre a música, conjugados com a abordagem teórica e metodologia clínica adotadas pelo terapeuta (SAMPAIO; SAMPAIO, 2005).

Qualquer que seja a necessidade clínica do paciente e o ambiente em que o processo clínico ocorre, todo processo clínico musicoterapêutico busca uma mudança, uma transformação no estado do paciente para que ele alcance uma melhor condição de saúde. Austin e Dvorkin (1998) descrevem que o conceito de resistência, embora de origem psicanalítica, vem sendo utilizado em Musicoterapia há várias décadas e configura um modo pelo qual o paciente se opõe ao processo terapêutico para se defender das mudanças que este produz ou pode proporcionar. Em Musicoterapia a resistência pode ocorrer tanto em momentos de verbalização como no próprio fazer musical, incluindo a recusa a tocar ou cantar (de modo geral ou até mesmo a utilizar um instrumento musical ou estilo musical específico), a falta de engajamento emocional na produção musical, a contradição entre o afeto expresso pela música e o afeto vivenciado e expresso pelo paciente, o uso recorrente de estruturas musicais conhecidas para evitar explorações musicais, a evitação de dialogar verbalmente sobre a experiência musical compartilhada, dentre outras ações e atitudes. Austin e Dvorkin 
(1998) consideram que a experiência musical pode ocorre em público, mas a sensação que ela produz é sempre particular e interna. O compartilhamento desta experiência com um terapeuta pode ser vivenciado como um momento de partilha tão íntimo que pode gerar medo, vergonha, culpa e ambivalência em relação a esta intimidade, dentre outros sentimentos, que podem levar o paciente a evitar a relação com o outro. Caberá ao musicoterapeuta reconhecer a presença da resistência e lidar com ela de acordo com as condições e particularidades daquele caso clínico específico.

Bruscia (2000) descreve o processo clínico musicoterapêutico como um conjunto de intervenções sistemáticas, planejadas, longitudinais e sequenciais. Estas intervenções são implementadas pelo musicoterapeuta e pretendem conduzir o paciente a uma alteração em seu estado de saúde por meio de engajamento do paciente em uma experiência musical coativa (com o terapeuta) no contexto de uma relação terapêutica. Neste processo, o paciente irá de um "estado atual” de menos saúde, ou de pior condição de saúde, para um "estado pretendido" de mais saúde, ou de melhor condição de saúde. Podemos utilizar, então, a imagem de uma jornada para descrever o processo terapêutico (ver Figura 1). O paciente parte de um lugar de "menos saúde" e, com o apoio do terapeuta, busca um lugar de "mais saúde", que terá como referência de chegada os objetivos terapêuticos que terapeuta e paciente pretendem alcançar. O ponto de partida será conhecido e descrito a partir de uma avaliação diagnóstica musicoterapêutica. Já o plano de atendimento musicoterapêutico constitui, nessa imagem, um mapa que descreve o ponto de partida, o ponto de chegada e a previsão de caminho que paciente e terapeuta irão percorrer.

\section{Processo Musicoterapêutico (como percurso)}

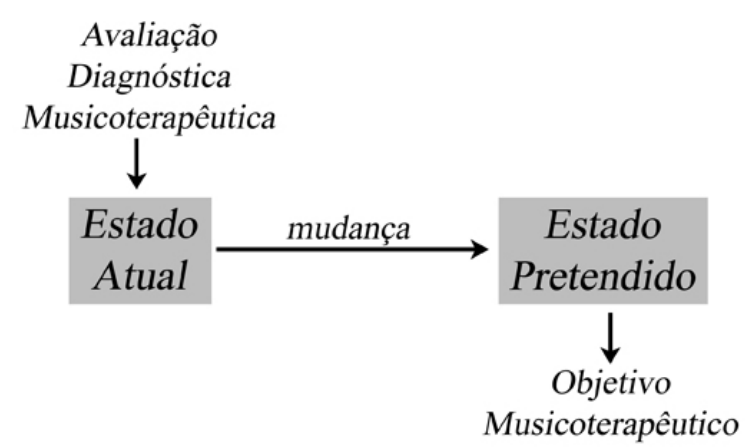

Figura 1: Representação esquemática do Processo Musicoterapêutico, no qual o paciente se engaja em uma experiência musical no contexto de uma relação terapêutica a fim de obter uma mudança em seu estado de saúde

Além da Avaliação Diagnóstica Musicoterapêutica inicial, que fornece uma compreensão do estado atual de saúde e desenvolvimento do paciente, devem ocorrer ao longo do processo clínico musicoterapêutico outros momentos em que a condição de saúde do paciente seja reavaliada, como um todo ou em aspectos específicos, para que o terapeuta possa compreender o caminho que já foi percorrido até então, bem como quais os novos passos que precisarão ser dados para ir ao encontro do objetivo terapêutico traçado. Deste modo, podem ser considerados quatro momentos em que a Avaliação Musicoterapêutica possa ocorrer:

1. No início do processo clínico, como Avaliação Diagnóstica inicial, no qual se busca descrever e compreender o estado atual de saúde do paciente, bem como suas limitações e potenciais; 
2. Ao final do processo clínico, para verificar se os objetivos terapêuticos foram alcançados e, portanto, se o processo clínico pode ser finalizado;

3. Ao longo do processo clínico, de modo a descrever e acompanhar o percurso terapêutico transcorrido, isto é, as mudanças que ocorreram no estado de saúde ao longo do processo clínico, bem como verificar se o processo clínico está efetivamente se dirigindo aos objetivos traçados, e, em última instância, até mesmo para verificar se tais objetivos continuam sendo pertinentes, uma vez que o paciente mudou durante este percurso; e

4. Acompanhamento após o encerramento do processo clínico, também muitas vezes denominado como follow up, no qual verifica se os efeitos do tratamento perduram após o encerramento do processo e se o paciente necessita, eventualmente, retomar algum tratamento para manter ou restaurar uma boa condição de saúde.

No International Dictionary of Music Therapy (KIRKLAND, 2013), são encontrados dois verbetes em língua inglesa que estão relacionados ao termo "Avaliação Diagnóstica": Assessment e Evaluation. O primeiro termo, Assessment, diz respeito ao que denominamos neste artigo como Avaliação Diagnóstica Musicoterapêutica Inicial, mas também a verificação se a Musicoterapia pode ser uma abordagem de tratamento adequada para o paciente e como o processo clínico musicoterapêutico está ocorrendo. Por sua vez, Evaluation está associado à busca de evidências de que houve mudanças no paciente que lhe levaram a uma melhor condição de saúde, servindo também como um momento de reflexão do musicoterapeuta sobre as intervenções realizadas e os métodos aplicados e para uma revisão e atualização dos objetivos terapêuticos.

Na literatura musicoterapêutica são encontrados diversos modelos e protocolos de avaliação, alguns dos quais possuem caráter mais quantitativo, de medida, enquanto outros, mais qualitativo, de descrição e compreensão. Há ainda, alguns modelos e protocolos que podem ser utilizados tanto de modo quantitativo como qualitativo. Por exemplo, dentre os modelos e protocolos de avaliação clínica musicoterapêutica que podem ser utilizados com crianças e adolescentes com distúrbios do desenvolvimento e que possuem um caráter mais qualitativo, podemos citar o Continuum of Awareness (BOXILL, 1985) e a Testificação (BENENZON, 1985). Dentre aqueles com caráter mais quantitativo, podemos encontrar os Perfis Individualizados de Avaliação Diagnóstica Musicoterapêutica [Individualized Music Therapy Assessment Profile] (IMTAP) (BAXTER et al., 2007) e o Modelo Comportamental de Avaliação de Hanser (HANSER, 1999). E, por sua vez, dentre os que podem ser utilizados tanto quantitativamente como qualitativamente, as Escalas Nordoff-Robbins (NORDOFF; ROBBINS; MARCUS, 2007) e os Perfis de Avaliação Diagnóstica Improvisacional [Improvisational Assessment Profiles] (IAP) (BRUSCIA, 1987). Essa variedade de instrumentos pode ser explicada devido a diferentes propostas clínicas (de acordo com a base conceitual) que se desdobram em diferentes focos clínicos, tipos de população (crianças, adolescentes, adultos, idosos), tipos de condição clínica, tipos de variáveis observadas e latentes em jogo, modos de coleta, análise e interpretação de dados etc. No entanto, Gattino et al. (2016) ressaltam que apenas poucos dos modelos de avaliação diagnóstica musicoterapêutica existentes já passaram por processos consistentes de validação e, quando couber, de tradução e adaptação para uso em outros países.

Cada modelo de avaliação possui uma base teórica que inclui um conceito de Homem, de Música e de Saúde, e, como decorrência disto, elenca áreas de avaliação que podem incluir, dentre outras, as habilidades musicais, as formas de resposta à música, a personalidade, as relações interpessoais, o comportamento, a biografia (história de vida), as habilidades motoras, de comunicação e de cognição e a expressão afetiva (BARCELLOS, 2016; BAXTER et al., 2007; BENENZON, 1985; BOXILL, 1985; BRUSCIA, 1987; COSTA, 
1989, 1995; HANSER, 1999; NORDOFF; ROBBINS; MARCUS, 2007; WIGRAM; PEDERSEN; BONDE, 2002).

Segundo Sampaio (2015), a avaliação musicoterapêutica pode coletar dados do fazer musical (comportamento do paciente durante a produção musical) em musicoterapia, dados sobre a relação terapêutica e dados musicais (o produto do fazer musical), quer o paciente e o terapeuta estejam interagindo de modo ativo, com os dois participando do fazer musical, ou quando um deles está de modo receptivo (apenas um toca e o outro somente observa/escuta). Sampaio $(2002,2007)$ considera que no fazer musical durante o processo musicoterapêutico há um encontro do paciente com o terapeuta em um território que é ao mesmo tempo musical e clínico, havendo demandas e forças destes dois tipos. O musicoterapeuta deve, portanto, conjugar as condições clínicas do paciente com suas possibilidades de expressão musical na seleção e na condução de atividades musicais que permitam ao paciente mudar seu estado de saúde a partir deste encontro. Acontece, neste momento, um processo de comunicação musical e no fazer musical que corresponde a uma coordenação de ações do musicoterapeuta e do paciente, e as resultantes sígnicas deste processo de comunicação pode também ser analisada por meio de análises semióticas ${ }^{2}$. Por conseguinte, quando o produto do fazer musical do terapeuta e/ou do paciente no processo musicoterapêutico é uma canção, propomos a utilização do modelo de Semiótica da Canção, desenvolvido por Luis Tatit, como base teórica para a avaliação musicoterapêutica.

\section{Por quê Canção? E por quê Semiótica da Canção?}

Segundo Podlipniak (2017, p. 542-543, tradução nossa),

Embora a diversidade mundial da música revele a flexibilidade cultural do Homo sapiens em relação à conduta musical, o fato de pessoas de todas as culturas conhecidas cantarem (NETTL, 2000) e poderem reconhecer música sem treinamento explícito (TILLMANN, 2005) sugere que a musicalidade seja parte do legado biológico humano.

Cantar é uma habilidade inata que vai sendo desenvolvida a partir da experiência social e que possui alguns universais, tais como: a presença de uma pulsação ou um senso de pulsação; o uso de três ou quatro tons (em geral) para caracterizar minimamente uma melodia; a noção de uma estrutura formal básica; a presença de um gênero específico para a infância (canções de ninar); e, uma hierarquia tonal, no qual algumas alturas funcionam como base ou referência sobre a qual as outras se relacionam e formam um contorno melódico, dentre outras (PERETZ, 2006, p. 6-7).

Para Ruud (2005, p. 9), desde a infância, nos relacionamos com a canção e com a composição de canções por meio de recriações, improvisações, paródias, composições propriamente ditas e, principalmente, pela identificação com as canções e com os cantores. O texto da canção fornece uma experiência simbólica que permite representar o mundo e usar metáforas para compreender o sentido do que acontece conosco. De acordo com Bruscia (1987, p. 516, tradução nossa), "enquanto instrumento individual do corpo, a voz estende o Eu Físico e projeta uma identidade sonora do Eu Interior”. Além disso, na musicoterapia,

Parece que a canção dá ao cliente um novo contexto, uma liberdade e uma força para ultrapassar suas vulnerabilidades. A forma da canção não apenas proporciona uma gama de possibilidades de auto expressão, mas igualmente permite um modo de encontrar e trabalhar com os temas e relações que ficaram congelados por muito tempo. A composição de canções fornece um contexto estético que convida os clientes a 
explorar, dentre de um novo enquadre, a sua vida, suas possibilidades, suas perdas e suas aspirações. (RUUD, 2005, p. 10, tradução nossa, grifo do autor).

Sampaio (2010) considera que a aplicabilidade da canção na Musicoterapia pode ser explicada por vários fatores: há um repertório rico, amplo e de fácil acesso a pacientes e terapeutas; pelo fato do cantar ser uma prática social comum, a canção favorece a interação na relação terapêutica; cantar é um hábito mais comum do que tocar um instrumento; a interação entre letra e música na canção favorece a expressão, a apreensão, a fixação e organização de conteúdos diversos; e, a canção, por ter uma estrutura familiar e previsível, pode favorecer a interação terapêutica de modo a trazer menor ansiedade e insegurança ao paciente (BARCELLOS, 2005), dentre outros motivos. Desde a da década de 1990, muitos musicoterapeutas têm sistematicamente se dedicado ao estudo do uso das canções em musicoterapia e sua aplicação com populações diversas, e, por conseguinte, desenvolvido conceitos, princípios e protocolos de uso, tais como os conceitos de Canção Desencadeante (BRITO, 2001), de Canção Âncora (CIRIGLIANO, 1998, 2004), e de Territórios Existenciais em Música (MILLECCO, 1997) e os protocolos de uso clínico de canções da Abordagem Plurimodal de Musicoterapia (SCHAPIRA et al., 2007), do Modelo Musicoverbal de Musicoterapia (MILLECO FILHO; BRANDÃO; MILLECCO, 2001), da Carta de Canções (BRANDALISE, 1998), da Associação Livre Cantada e do Vocal Holding (AUSTIN, 1999, 2002), do Canto na Estimulação Multimodal de Bebês Prematuros (SHOEMARK, 1999, 2014), da improvisação e de canções e estórias no trabalho em Saúde Mental com crianças e adolescentes (OLDFIELD, 2006; OLDFIELD; FRANKE, 2005), da composição de canções com pacientes adultos hospitalizados (DILEO, 1999; DILEO; MAGILL, 2005), do trabalho com canções na reabilitação neurológica de crianças e adultos (BAKER; TAMPLIN; KENNELLY, 2006; THAUT; HOEMBERG, 2014), dentre outros.

Segundo Tatit (1996, p. 9), "cantar é uma gestualidade oral, ao mesmo tempo contínua, articulada, tensa e natural, que exige um permanente equilíbrio entre os elementos melódicos, linguísticos, os parâmetros musicais e a entonação coloquial”. Deste modo, quem canta, ao cantar, não somente expressa um conteúdo por meio do texto da canção, mas também pelo modo como canta, incluindo tanto os aspectos musicais rítmicos, melódicos, harmônicos e timbrísticos, como a gestualidade e a corporeidade. Podemos considerar, então, que a força expressiva do canto na canção pode, por um lado, potencializar os conteúdos expressivos do discurso verbal como, por outro, favorecer este discurso vir à tona ao trazer previsibilidade, equilíbrio e forma, o que, conscientemente ou não, irá por sua vez favorecer a expressão de conteúdos internos.

[...] na junção da sequência melódica com as unidades linguísticas, ponto nevrálgico de tensividade, o cancionista tem sempre um gesto oral elegante, no sentido de aparar as arestas e eliminar os resíduos que poderiam quebrar a naturalidade da canção. Seu recurso maior é o processo entoativo que estende a fala ao canto. Ou, numa orientação mais rigorosa, que produz a fala no canto.

[...] As tensões locais são produzidas diretamente pela gestualidade oral do cancionista (compositor ou intérprete), quando se põe a manobrar, simultaneamente, a linearidade contínua da melodia e a linearidade articulada do texto. O fluxo contínuo da primeira adapta-se imediatamente às vogais da linguagem verbal mas sofre atrito das consoantes que interrompem sistematicamente a sonoridade. Uma força de continuidade contrapõe-se, assim, a uma força de segmentação (em fonemas, palavras, frases, narrativas e outras dimensões intelectivas), fundando um princípio geral de tensividade que a habilidade do cancionista vai administrar e disseminar ao longo da obra. 
O compositor, como bom malabarista, aproveita em geral a força das duas tendências exercitando ora a continuidade, ora a segmentação. (TATIT, 1996, p. 9-10)

Peretz, Champod e Hyde (2003) propõem um modelo de processamento cognitivo de canções que ocorre em três módulos paralelos e semi-independentes: rítmico, melódico e verbal. O resultado do processamento nos três módulos individualmente e das relações entre eles seria responsável pelo reconhecimento da canção, pelo reconhecimento, expressão e vivência do caráter emocional da canção, da recuperação mnemônica do texto e da melodia, dentre vários outros aspectos da recepção, compreensão, memorização, recapitulação e (re)produção de canções. Esse modelo tem sido utilizado como um fundamento neuropsicológico para a compreensão de processos cognitivos no ato de cantar e como uma das ferramentas diagnósticas para a detecção de amusia congênita (uma desordem, de origem genética, do processamento neurológico de estímulos sonoros) (VUVAN et al., 2017).

Para Tatit (1996), enquanto a fala é descartável e irregular em sua sonoridade, a canção organiza, articula e fixa esta sonoridade, gerando uma espécie de lastro que estabiliza as sonoridades segundo parâmetros rítmicos, melódicos, harmônicos e timbrísticos, trazendo uma segunda cadeia significante ao discurso verbal, atrelada a esta, mas que pode enfatizá-la ou contradizê-la. Justamente nesse contraponto entre os movimentos de linearidade e segmentação, de continuidade e descontinuidade, de tensão e distensão, de conjunção ou disjunção entre o discurso verbal e o musical, é que surge a potência expressiva que torna a canção tão rica e poderosa para uso terapêutico. Ao cantar, quem canta assume o papel de interlocutor, mas, também, ao mesmo tempo, de ouvinte (de seu próprio discurso), além de fazer vibrar seu corpo (MILLECO FILHO; BRANDÃO; MILLECCO, 2001) e, desse modo, presentifica-se pela voz que entoa, pelo discurso verbal e musical que emite, pela escuta de sua própria voz e pela percepção da vibração de seu corpo ao cantar.

A partir da descrição de Bruscia sobre os fundamentos da Musicopsicoterapia (BRUSCIA, 1998), podemos inferir que em Musicoterapia pode haver três formas de discurso que podem ser nomeadas como Discurso Musical, Discurso na Música e Discurso sobre a Música. No Discurso Musical, o sentido da experiência musical no contexto da relação terapêutica (entre paciente e terapeuta) provém do significado musical intrínseco, a partir da percepção, vivência e processamento das estruturas musicais e da relação na experiência musical. No Discurso na Música, podemos ter tanto a música instrumental com abordagem referencial (isto é, se referindo a algo fora dela, como uma metáfora ou uma analogia) ou a canção, na qual a fala se torna música. Pode haver ainda um Discurso sobre a Música, quando paciente e terapeuta verbalizam sobre a experiência musical como produto ou processo (fazer musical).

Apesar de Tatit $(1996,1997,2001)$ reconhecer que a extensão do sentido produzido por uma canção certamente é inatingível em sua totalidade por uma análise, tal autor propõe que uma análise, no modelo de Semiótica da Canção que construiu, pode explicar alguns aspectos da produção de sentido. Em Musicoterapia, quando aliamos a análise semiótica da canção trazida e recriada pelo terapeuta e/ou paciente ou por uma canção composta pelo paciente (com o apoio do terapeuta) com uma descrição do momento do processo terapêutico no qual aquela canção foi recriada ou composta, podemos ter em mão um poderoso instrumento para avaliação e compreensão daquele momento do processo terapêutico e/ou do próprio processo terapêutico.

A partir da década de 1980, Luiz Tatit busca ultrapassar modelos tradicionais de análises literária, etnomusicológica e sistemática musical para criar um modo singular de tratar as canções, trazendo para a prática de análise musical contribuições de teóricos como Saussurre, Hjelmslev, Greimas e Zilberberg. Em um de seus primeiros livros, A Canção: 
Eficácia e Encanto (TATIT, 1986), encontramos o cerne do que propomos para a análise semiótica musicoterapêutica da canção, a persuasão em suas instâncias figurativa, passional e decantatória, que logicamente possui desenvolvimentos e desdobramentos posteriores, tais como aspectos próprios de conjunção e disjunção na melodia, no texto e entre os dois (TATIT, 1994) e o quadrado semiótico de sentido do texto (TATIT, 2001).

Segundo Tatit (TATIT, 1986, 1994), a eficácia de uma canção depende fundamentalmente da adequação e compatibilidade entre o seu componente melódico e seu componente linguístico. Eficácia, neste contexto, se refere ao êxito de uma comunicação entre o locutor e o ouvinte, e tal êxito depende de alguns processos de persuasão dentre os quais está a persuasão passional e os modos de "sobremodalização".

Nessa abordagem teórica, há quatro modos básicos de relação entre as pessoas e o mundo, que são designados pelos verbos: querer, dever, saber e poder. As modalidades funcionam como fragmentos de intenção de comunicação já que toda ação no mundo pressupõe algum desses verbos, que ninguém faz algo que não quer, não deve, não sabe e não pode. O locutor quer/deve/sabe e/ou pode fazer com que o ouvinte queira/deva/saiba e/ou possa ouvir sua canção. Esse encadeamento modal do locutor sobre o ouvinte é um caso de sobremodalização presente em toda comunicação de canções. Quando há compatibilidade modal do texto com a melodia e esta for suficientemente persuasiva, a sobremodalização se completa, ou seja, há uma cumplicidade emocional do ouvinte com o interlocutor da narrativa da canção (TATIT, 1994), isto é, o ouvinte sente/pensa o que o locutor queria transmitir para ele de modo preciso ou muito aproximado. Como exemplo, a respeito das "canções românticas", Tatit afirma:

A configuração de um estado passional de solidão, esperança, frustração, ciúme, decepção, indiferença etc., ou seja, de um estado interior, afetivo, compatibiliza-se com as tensões decorrentes da ampliação de frequência e duração. Como se à tensão psíquica correspondesse uma tensão acústica e fisiológica de sustentação de uma vogal pelo intérprete. $\mathrm{O}$ prolongamento das durações torna a canção necessariamente mais lenta e adequada à introspecção. Afinal, a valorização das vogais neutraliza parcialmente os estímulos somáticos produzidos pelos ataques das consoantes. O corpo pode permanecer em repouso, apenas com um leve compasso garantindo a continuidade musical. (TATIT, 1997, p. 103)

Na análise da canção, é preciso detectar o foco de tensão causador do estado emocional relatado pelo locutor, que quase sempre está relacionado aos mecanismos de conjunção e disjunção dispostos na narrativa. Esta análise pode ser feita complementarmente por meio do quadrado semiótico, que consiste em um modo diagramático de representar os temas principais e as relações entre eles, apresentando-os em uma estrutura profunda de tensões e sentidos (NÖTH, 1996; TATIT, 2001).

A persuasão figurativa (TATIT, 1986, 1994; TATIT; LOPES, 2008) refere a uma tentativa de fazer com que o canto se assemelhe a uma comunicação do dia a dia. Nela, estão contidos elementos como a presença de "dêiticos", termo que designa elementos linguísticos que servem para caracterizar uma situação de locução, em seus aspectos temporais (quando) e espaciais (onde), mas também de quem está presente (“eu”, "você”, "ele” etc.) e de relações de poder entre tais pessoas. Há dêiticos que simulam na fala um gesto ("assim”, "deste modo", "pra lá" etc.) ou demonstram algo ("nesta”, "aquele” etc.), dentre vários outros. Além disso, a própria forma do texto verbal se assemelha a um monólogo (que supõe um ouvinte e tenta envolvê-lo na narrativa) ou um diálogo. 
Já na persuasão decantatória (TATIT, 1986, 1994), são encontrados elementos musicais reiterativos que dão ordem, unicidade e sentido à melodia, assim como favorecem a compatibilidade prosódica entre melodia e letra da canção e a compatibilidade de caráter emocional entre elas.

\section{O Protocolo de Avaliação Semiótica de Canções em Musicoterapia}

Segundo Kirkland (2013, p. 103), um protocolo é um conjunto de passos e/ou componentes de uma intervenção, de um tratamento, de um experimento de pesquisa ou de uma avaliação musicoterapêutica. Para Kirkland (2013), um protocolo pode ser tanto implementado devido a sua eficácia estabelecida como antecipada, baseada em pesquisa anterior e/ou prática clínica baseada em evidência.

Um protocolo de avaliação musicoterapêutica também pode ser concebido como um mediador entre a percepção do terapeuta e a ação do paciente no setting visto que direciona o que, como e quando o musicoterapeuta deve observar e registrar. Ele dá suporte técnico e fundamentação teórica e, portanto, orienta as ações e intervenções do musicoterapeuta, possibilitando um registro organizado das ações e eventos que ocorrem no setting musicoterapêutico. Portanto, um protocolo de avaliação musicoterapêutica facilita a interpretação sobre a condição e a necessidade clínica do paciente e, por conseguinte, favorece o planejamento do processo terapêutico e sua implementação.

A partir de várias análises semióticas de canções realizadas por Tatit, seus alunos e colaboradores (DIETRICH, 2008; MACHADO, 2012; SILVA, 2011; TATIT, 1996, 1997, 2001; TATIT; LOPES, 2008, dentre outros) foi estruturado um roteiro de análise pertinente ao contexto musicoterapêutico, em cinco passos.

I. Descrição resumida do contexto clínico. Neste momento o musicoterapeuta inicialmente elencará dados biográficos, clínicos e o contexto do paciente. A seguir relatará resumidamente o momento do processo musicoterapêutico em que a canção foi composta, ouvida ou recriada, descrevendo o objetivo clínico, o modo de intervenção etc.

II. Análise Semiótica da Letra e da Melodia. Contemplando: Análise das situações de conjunção e disjunção na narrativa (letra), na melodia e entre elas; os dêiticos presentes (ou a sua ausência); as modalizações e os estados emocionais (referidos na letra ou inferidos a partir dela) dos personagens da canção; o quadro semiótico e suas estruturas de tensões e sentido; a estrutura melódica e os processos de geração de sentido e persuasão decantatória; as relações entre letra e música e como os aspectos musicais podem atenuar, reforçar ou contradizer o conteúdo linguístico.

III. Análise do arranjo e da performance do cantor.

IV. Interpretações, a partir dos dados coletados e da análise semiótica musicoterapêutica da canção.

V. Inferências sobre as implicações presentes (o que o paciente apresenta com esta canção) e futuras para o processo clínico musicoterapêutico (quais os próximos passos a serem trilhados, a partir do reconhecimento do local atual).

É importante salientar que este protocolo não pode ser concebido como um esquema fechado e prescritivo. Os passos descritos acima não precisam necessariamente ser implementados nesta ordem, ficando o musicoterapeuta livre para utilizar o que for pertinente e do modo que for possível em função das necessidades clínicas do paciente e do contexto específico daquele momento do processo musicoterapêutico em que for utilizado. Por exemplo, em alguns casos pode-se enfatizar a análise da letra e, em outros, os arranjos e modos de interpretação (performance) do paciente ao fruir a canção. 


\section{Um exemplo: 0 processo musicoterapêutico de Paula}

A descrição do quadro de Paula, do processo terapêutico e da análise semiótica da canção em musicoterapia a seguir será narrado em primeira pessoa, pela voz do musicoterapeuta. Paula (nome fictício) foi encaminhada pela coordenadora pedagógica da escola pública onde estudava com uma queixa de dificuldades de aprendizagem e de problemas comportamentais em casa e na escola para a Clínica de Musicoterapia de uma universidade privada que fazia atendimentos gratuitos a pessoas com carência socioeconômica. Paula tinha 14 anos e tinha um irmão e uma irmã mais velhos. Estava morando com a mãe e o padrasto em uma edícula na casa de sua avó materna e seus irmãos moravam com uma tia, devido a dificuldades financeiras da família. O padrasto de Paula trabalhava como segurança e, sua mãe, como faxineira. Durante a entrevista inicial com Paula e sua mãe, a mãe justificava a dificuldade de aprendizagem, incluindo uma reprovação escolar, com um quadro de dislexia, mas não apresentou um laudo diagnóstico afirmando que o neurologista que consultara ainda estava avaliando o caso para verificar possíveis intervenções medicamentosas e/ou terapêuticas que seriam necessárias (SIC). A mãe também alegava que muitos dos problemas comportamentais na escola, que incluíam discussões verbais com outros estudantes e com professores e, em alguns momentos, até mesmo agressão física, seriam derivados da dislexia e da dificuldade de aprendizagem, uma vez que Paula ficava nervosa por não conseguir acompanhar o processo pedagógico como os outros alunos, o que a levava a alterações de humor e de conduta. Porém, desde os primeiros momentos da entrevista, notei que havia algo mal explicado sobre a situação familiar e que as dificuldades de comportamento e de aprendizagem talvez tivessem algum outro fator gerador ou complicador, além da eventual dislexia. Embora em algumas ocasióes durante a entrevista eu tivesse me dirigido diretamente a Paula para pedir mais informações sobre a escola, a família, o relacionamento com seus amigos etc., a mãe em várias ocasiões tomara a palavra e não deixara a filha falar. Tive a impressão de que ela precisava justificar as dificuldades da filha o tempo todo, como se já estivesse com um discurso prévio. As sessões ocorreram semanalmente em uma sala ampla, clara e ventilada com os instrumentos musicais e equipamentos tradicionais para atendimento musicoterapêutico: piano, teclado eletrônico, violão, instrumentos de percussão com altura definida e indefinida e aparelhagem de som.

Na primeira sessão destinada à avaliação diagnóstica musicoterapêutica por meio de atividades de recriação, improvisação e audição musical, os vários instrumentos musicais foram dispostos pela sala e Paula foi convidada a experimentá-los, porém se recusou a tocar. Alegou que já conhecia alguns, que não tinha interesse ou curiosidade e se limitou a comentar sobre o tempo em que participou da fanfarra em uma escola onde havia estudado anteriormente. Aproveitei, então, para perguntar sobre esta experiência, se ela gostava de tocar instrumentos, como eram as aulas de música nesta escola, como eram as atividades da fanfarra etc. Paula narrou alguns acontecimentos e respondeu a algumas de minhas perguntas, mas sem demonstrar grande envolvimento emocional com aquelas atividades ou com o diálogo. Nas sessões seguintes, Paula também se recusou a tocar e até mesmo a se aproximar dos instrumentos musicais e disse que queria apenas falar. Conversamos então sobre sua situação familiar, sobre sua escola e sua relação com outros alunos da escola e sobre suas amizades. Aos poucos, Paula foi descrevendo um quadro familiar de instabilidade financeira e de desestruturação familiar, havendo uma grande rivalidade entre sua mãe e uma tia materna, incluindo o modo como sustentar financeiramente e educar Paula e seus irmãos. Posteriormente, conversamos também sobre seus problemas de comportamento na escola que pareciam estar mais relacionados a intransigência, a intolerância e a fal- 
ta de diálogo (de Paula, dos professores, da Coordenação Pedagógica etc.) do que algo mais de fundo orgânico, como uma dislexia. É importante salientar que não descartei um possível diagnóstico de dislexia, mas considerei que era mais relevante para aquele momento abordar no processo terapêutico as dificuldades relacionais. Até a sétima sessão, não houve nenhuma atividade musical de improvisação, recriação ou composição. Somente ocorreram alguns poucos momentos de audição musical de músicas (tanto canções como músicas instrumentais de diversos estilos) que eu levava para escutarmos juntos como tentativa de fazer emergir algum conteúdo para que pudéssemos estabelecer um melhor contato e uma melhor interação.

Desde a segunda sessão, eu havia pedido para que Paula trouxesse músicas que ela gostava para escutarmos juntos e conversar sobre as músicas, mas somente na oitava sessão ela o fez. Trouxe um compact disc (CD) com diversas canções que tocavam usualmente em rádio, principalmente Rock e Pop internacionais. Pedi para que Paula escolhesse uma das músicas do CD e ela escolheu Welcome to my life da banda Simple Plan. Quando perguntei se Paula entendia a letra da música e o que havia naquela música que lhe agradava, Paula respondeu que não entendia inglês e nunca teve curiosidade de procurar uma tradução da letra. Alegou que gostava "da levada", pois a guitarra e a bateria lhe davam vontade de se mover, como se lhe dessem energia para caminhar. Encerrei a sessão pedindo a Paula que trouxesse novamente o CD com aquela música na semana seguinte para que pudéssemos ouvir novamente esta canção, conversar mais sobre ela e sobre música em geral.

Na nona sessão, ouvimos inicialmente Welcome to my life em silêncio, e então perguntei a Paula se ela gostaria de conhecer a tradução da letra. Durante uma nova escuta, fui então traduzindo a letra e Paula foi ficando com os olhos arregalados e alegou com surpresa: "Está falando de mim! Está falando da minha vida!”. Aproveitei a oportunidade para explicar a Paula sobre como música, tanto a canção como a música instrumental, pode falar muito sobre nossas vidas, e que cantar canções poderia ser um bom modo de dizer o que eventualmente não podemos ou não conseguimos contar com a fala. Cantamos algumas vezes Welcome to my life, à capella e com acompanhamento de violão ou teclado. Exploramos dinâmicas, intensidades, andamentos, tonalidade e algumas alterações melódicas para descobrir como Paula ficava mais confortável cantando aquela canção que falava tanto sobre sua vida e para que ela pudesse se apropriar dos sentimentos que emergiam durante a recriação musical. 


\section{Welcome to my life ( $1^{\mathrm{a}}$ parte)}

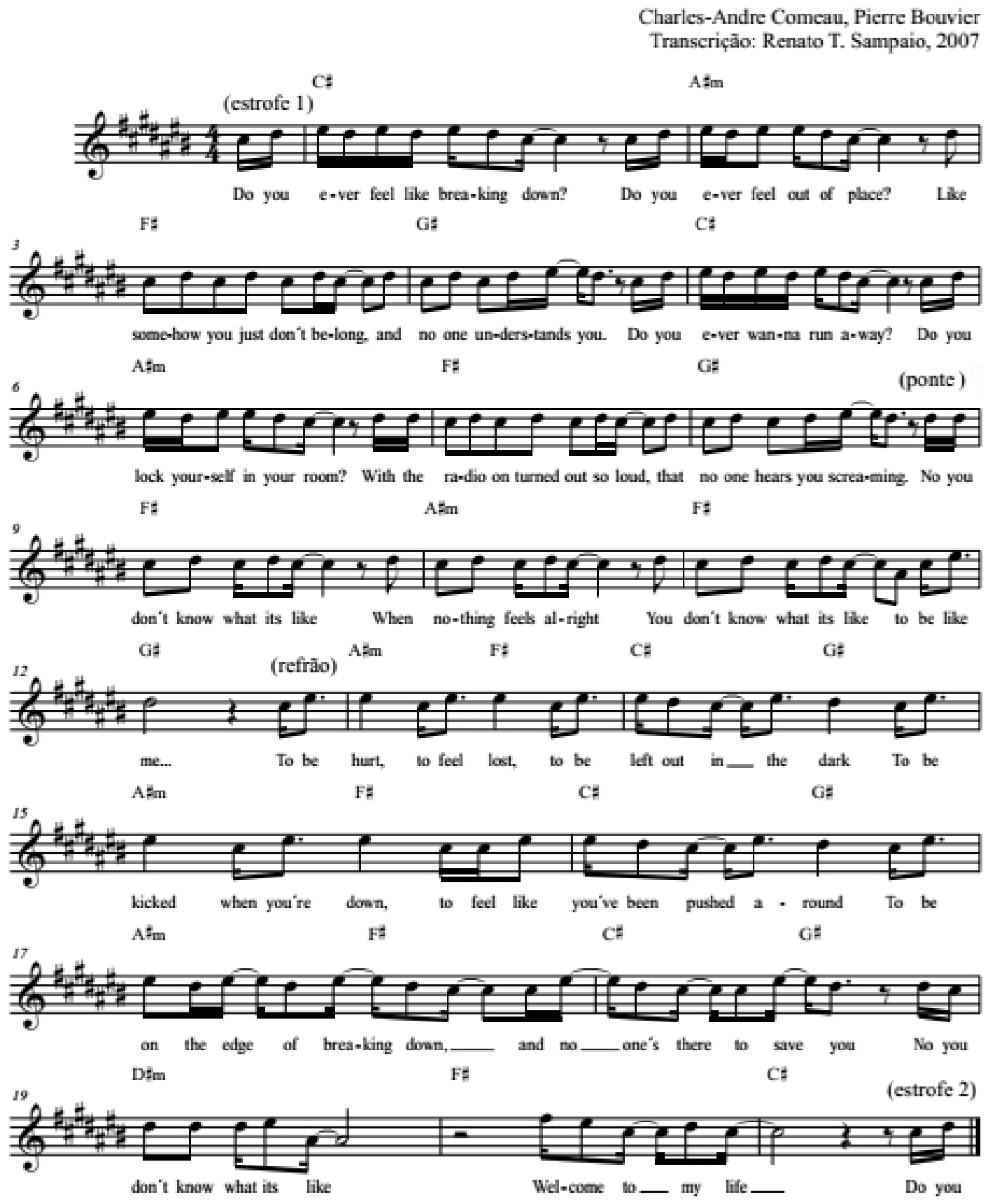

Ex.1: Transcrição da primeira parte (estrofe 1, ponte e refrão) da canção Welcome to my life.

Apresentamos a seguir uma breve análise semiótica musicoterapêutica da canção realizada entre as sessões oito e nove para aprofundar a compreensão da canção Welcome to my life e, por meio dela, do momento do processo de Paula. O Exemplo Musical 1 (Ex.1) apresenta uma transcrição da primeira parte de Welcome to my life, incluindo a primeira estrofe, a ponte e o refrão. O texto da canção é narrado em primeira pessoa do singular, o destinador, com um destinatário correspondente a segunda pessoa do singular. Na primeira estrofe, observamos várias perguntas que demonstram uma disjunção do destinador com as outras pessoas à sua volta e, em última instância, com o mundo. Ele se sente sozinho, fragilizado e no limite de "quebrar". Há uma carência de poder fazer as coisas que necessita para estar bem consigo e com os outros e há um reconhecimento desta situação, um saber sobre o 
seu estado e suas limitações. Há, ainda, um querer escapar do mundo, quer seja fugindo ou se trancando no quarto com a música alta. Na ponte, o destinador declara um não saber do destinatário sobre o que é estar nesta situação e um não poder entrar em empatia. O refrão aborda novamente a dor, o sofrimento, a carência e a impotência, isto é, novamente o destinador demonstra que sabe sobre seu estado, suas limitações e seu desamparo, e declara seu não poder transformar isso. O refrão termina com uma frase que poderia ser um convite ao contato com o outro, "Welcome to my life" ["bem-vindo à minha vida"], mas possui neste caso muito mais um senso de ironia e de crítica ao não reconhecimento do outro sobre o sofrimento vivenciado. O restante da canção possui a mesma estrutura de narrativa, apresentado um saber sobre a sua situação, um não saber do outro sobre como é sofrer, um não poder sair desta situação, um não poder entrar, estabelecer uma relação de conjunção com o outro etc. O texto apresenta poucos dêiticos, em sua maioria, temporais, mas indefinidos, tais como "alguma vez". Isso faz com que a canção se torne mais atemporal, apesar da narrativa (linguagem e conteúdo) se aproximar do tipo de discurso de adolescentes ou jovens adultos.

Em relação aos aspectos musicais, na estrofe e na ponte observamos frases melódicas que basicamente giram em torno de uma única nota (com ornamentos que poderiam ser descritos quase como mordentes ou apogiaturas) com breves declives nos finais de frase. As notas de apoio das frases são notas da tríade básica dos acordes de acompanhamento. No refrão, frases mais curtas com finais ascendentes dão um tom mais impulsivo à melodia, combinando com o caráter acusador do texto. O arranjo e a interpretação do cantor reforçam estas características de desabafo e acusação, auxiliando na caracterização da disjunção entre o destinador e o destinatário.

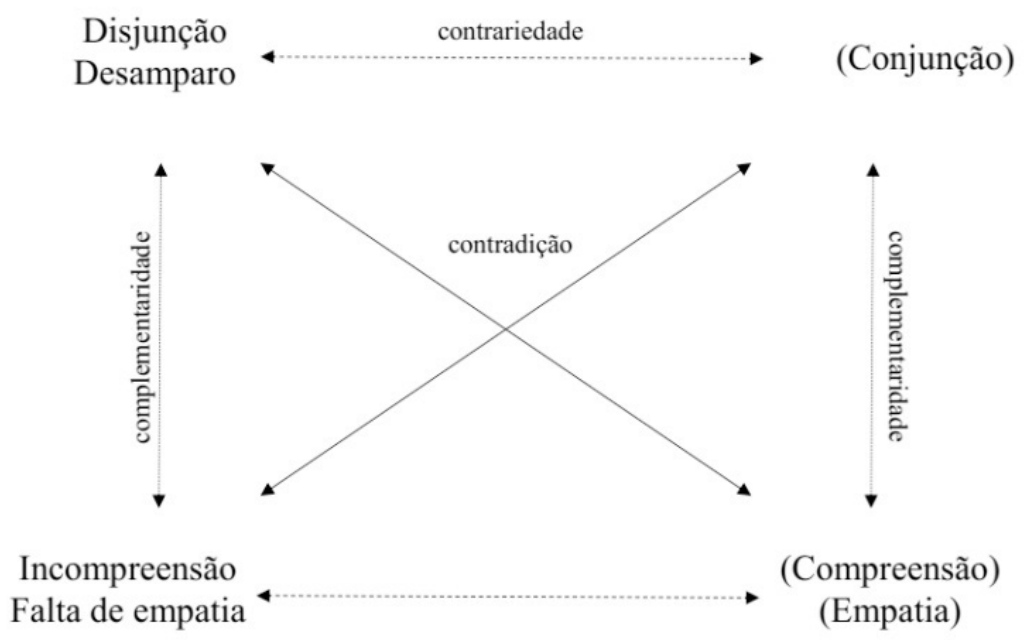

Figura 2: Quadrado semiótico para Welcome to my life

O quadrado semiótico para Welcome to my life (Figura 2) apresenta, no canto superior esquerdo, os elementos centrais do texto: o estado de disjunção e o desamparo que ele ocasiona. No canto superior direito, o estado de conjunção foi colocado entre parênteses, pois ele não é apresentado no texto da canção. No canto inferior esquerdo, os sentimentos de incompreensão e falta de empatia apresentados na canção são complementares ao estado de disjunção. No canto inferior, os estados de compreensão e empatia, ausentes no texto, foram colocados entre parênteses e contradizem o elemento central deste texto, o estado de disjunção. Pode-se, então, compreender que o texto apresenta os estados de valência negati- 
va e que o destinador carece de recursos, meios, condições e/ou oportunidades para alterar tal posição.

De posse dessas informações, pude inferir que a recusa para participar ativamente do fazer musical de Paula poderia configurar uma resistência e que todo o tempo que havia sido dado para conquistar confiança e proporcionar segurança até aquela sessão tinha sido válido para que, a partir dali uma nova qualidade de relação pudesse ser estabelecida tanto comigo como com a música. Nas sessões seguintes, Paula aceitou meus convites para explorar os instrumentos musicais e ocorreram várias pequenas improvisações não referenciais (onde o foco é o manuseio dos elementos musicais na experiência compartilhada) nas quais houve uma sedimentação da relação de confiança, de acolhimento e de disponibilidade para estar-com-o-outro. Após as improvisações, eu buscava dialogar sobre como era estar na experiência compartilhada com o outro e como se poderia conduzir estas experiências compartilhadas de modo a estabelecer relações de conjunção com o outro. Na décima quinta sessão, terapeuta e paciente se engajaram em uma longa improvisação livre, com boa qualidade de interação e de escuta um do outro. Paula demonstrava estar pronta para uma nova fase do processo.

Na décima sétima sessão, Paula chegou muito alegre e sorridente. Alegando que estava feliz e tão "de bem com a vida" que nem sua mãe, se quisesse, conseguiria atrapalhá-la. Propus então que compuséssemos uma canção para expressar este estado. Fomos ao teclado e, após algumas experimentações, uma canção começou a ser delineada. Paula trazia o conteúdo da letra, o terapeuta estabelecia uma harmonia e Paula construía a melodia e o texto da canção ao mesmo tempo. O processo de composição da canção ${ }^{3}$ durou menos de 10 minutos e o título foi o último elemento a ser definido. Cantamos algumas vezes a canção, explorando a interpretação vocal e gestual para que Paula ficasse confortável cantando e, ao mesmo tempo, trazendo à tona toda a carga emocional contida nessa canção.

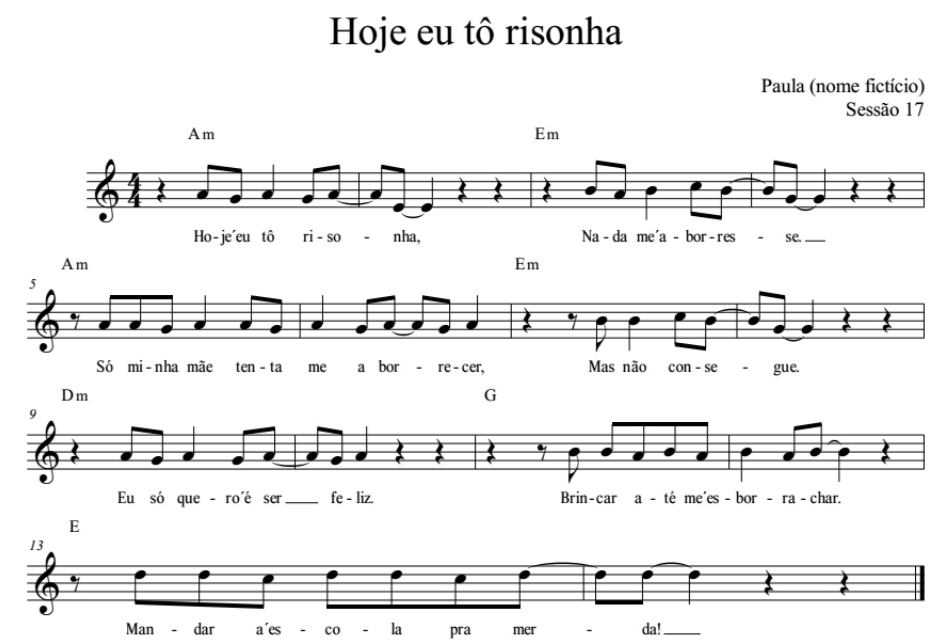

Ex.2: Transcrição da canção Hoje eu tô risonha, composta na $17^{a}$ sessão por Paula, com auxílio do musicoterapeuta. Fonte: Autor, ano.

A canção Hoje eu tô risonha está estruturada em duas partes. Nos compassos um a oito, quatro frases melódicas praticamente idênticas (embora adaptadas à harmonia) descrevem o estado atual de Paula. Ela sabe que está feliz, sabe que tem poder para se manter neste estado e, mesmo que sua mãe queira estragar sua felicidade, ela não tem poder para tal. Paula está em plena conjunção consigo mesmo e uma eventual disjunção com sua mãe 
não lhe afetaria. Na segunda parte da canção, compassos 9 a 14, Paula expressa querer ser feliz e demonstra saber como alcançar tal felicidade, ao brincar e ao se afastar do que lhe faz mal (a escola). Em contraste com a primeira canção, esta traz o dêitico temporal logo no início da narrativa caracterizando bem o tempo presente.

A estrutura harmônica da primeira parte possui um caráter afirmativo, onde o centro harmônico (Am) é mantido uma vez que o outro acorde (Em) também poderia ser caracterizado como tônica. Deste modo, mais do que um percurso harmônico que descreve uma trajetória de um lugar ao outro, este trecho se mantém harmonicamente no mesmo local, dando "coloridos" harmônicos diferentes às diversas frases musicais, o que traz um certo movimento, porém não descreve um caminho de um lugar a outro. Como a melodia se apoia em notas dos acordes e decai ao final (com exceção da terceira frase), de um modo geral há uma baixa tensão melódica, o que condiz com um estado de bem-estar e de conjunção consigo mesmo. É interessante notar que a estrutura das frases melódicas da primeira parte de Hoje eu estou risonha é semelhante à das frases melódicas da primeira estrofe de Welcome to my life. Como mencionado anteriormente, são frases que giram em torno de uma nota de referência, presente no acorde de acompanhamento, com ornamentos e finais de frase descendentes para outra nota básica do acorde. A diferença reside, no entanto, que em Hoje eu estou risonha há mais saltos, e como há menos texto em cada frase, as durações são mais longas, com um andamento um pouco mais acelerado, derivando um caráter emocional de valência mais positiva.

A primeira frase da segunda parte mantém aproximadamente o mesmo contorno melódico da primeira, porém há um início de mudança de percurso harmônico que vai se distanciando do contexto emocional da primeira parte. A harmonia vai aumentando a tensão aos poucos até chegar a um acorde de dominante na última frase, ao mesmo tempo em que as frases melódicas terminam em movimento ascendente, e vão paulatinamente ficando mais agudas, o que também aumenta a tensão. Ao longo deste trecho, o aumento gradual da tensão melódica e harmônica parece ir acumulando energia suficiente para possibilitar a ação de "mandar a escola para merda!" na última frase, o que afastaria de Paula boa parte dos elementos estressores. Salienta-se que a última frase termina no sétimo grau do acorde de E, porém, esta tensão não é sustentada. Durante a exploração gestual para a interpretação, Paula utiliza neste momento da canção gestos semelhantes ora a arremessar, ora a explodir.

Ainda a respeito da tensão que é apresentada na segunda parte da canção, podemos considerar que ela já estava presente na primeira parte, mesmo em um estado de conjunção, talvez de modo inconsciente ou esta tensão realmente vai sendo construída e acumulada na segunda parte para permitir o ápice com a explosão? Compreendi, na época, que o acumulo de tensão era necessário como empoderamento e energização necessária para que Paula pudesse agir no sentido de buscar o que deseja e afastar o que não deseja. 


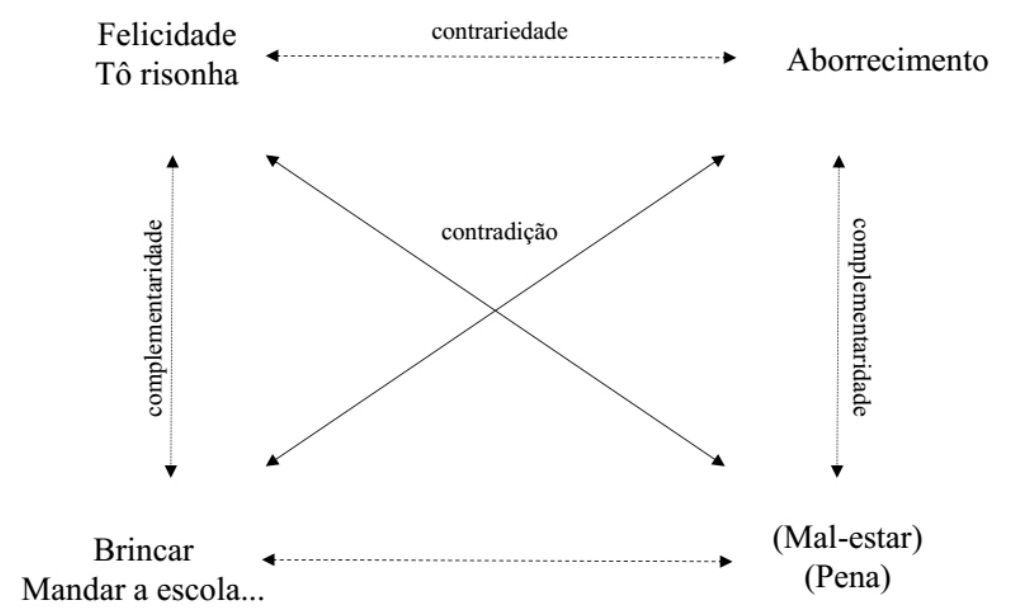

Figura 3: Quadrado semiótico para Hoje eu tô risonha

O quadrado semiótico para Hoje eu tô risonha (Figura 3), por sua vez, apresenta, no canto superior esquerdo, os elementos centrais do texto: o estado de felicidade, de conjunção. No canto superior direito, o aborrecimento que pode ser tentado pela mãe contraria tal estado, mas, embora esta possibilidade esteja presente no texto, há uma chance muito pequena de ela acontecer devido ao empoderamento do destinatário. O brincar e o "mandar a escola para a merda!” se posicionam em complementaridade com o estado geral de conjunção, pois permitem perpetuar tal estado. Os sentimentos de mal-estar e pena, por não serem apresentados na canção, foram descritos entre parêntese. Deste modo, o tema geral da segunda canção importante no processo terapêutico de Paula, Hoje eu tô risonha, se opõe ao tema geral da primeira canção, Welcome to my life, demonstrando uma mudança de estado e de modo de ser e de se relacionar com as outras pessoas. É interessante notar a semelhança do contorno melódico presente na canção Welcome to my life e na canção Hoje eu tô risonha. Mais do que um elemento de estilo, podemos considerar que houve uma influência da primeira canção sobre a seguinte, mesmo havendo uma distância temporal significativa de aproximadamente dois meses (oito sessões).

O processo musicoterapêutico de Paula prosseguiu explorando essas duas posições, de um lado, desamparo e disjunção com os outros, e, por outro, de conjunção consigo mesmo, de bem-estar e de empoderamento, almejando alcançar possibilidades de relações interpessoais mais saudáveis e mais frutíferas para o seu desenvolvimento pessoal e social. Logicamente, houve altos e baixos neste processo, bem como avanços e recaídas até o momento de encerramento do processo musicoterapêutico, dali a alguns meses pela impossibilidade financeira de Paula ir aos atendimentos pois, mesmo o atendimento musicoterapêutico sendo gratuito, Paula precisava gastar com transporte e sua família não tinha condições de continuar arcando com tal despesa.

\section{Discussão}

No início do processo musicoterapêutico, a paciente estava bastante resistente a engajar-se na atividade musical compartilhada (cantar, tocar e até mesmo a ouvir música) ou mesmo a permitir a vinculação com o musicoterapeuta. A postura adotada pelo musicoterapeuta de aceitação, de acolhimento e de respeito ao tempo da paciente parece ter favorecido a criação do vínculo e, aos poucos, permitido a interação na experiência musical compartilhada. O momento crucial para a mudança no relacionamento entre terapeuta e 
paciente bem como entre a resistência para engajar-se na atividade musical compartilhada e a permissão para ingressar nela foi a tradução da canção Welcome to my life na nona sessão. A escolha desta canção, mesmo que inconsciente e sem grande engajamento emocional, demonstrou que "ninguém canta por acaso" (MILLECO FILHO; BRANDÃO; MILLECCO, 2001, p. 91) e que cada pessoa, quando verdadeiramente envolvida no processo musicoterapêutico, busca na música aquilo que necessita para a expressão de seus sentimentos e emoções. A canção Welcome to my life permitiu à paciente dar-se conta de quem é, de como estava sendo-no-mundo e de que é possível comunicar com a música e, a partir de então, compartilhar a experiência musical em busca de novas formas de ser e de se relacionar. A análise semiótica da canção pelo musicoterapeuta, por sua vez, lhe permitiu compreender os temas sobre os quais poderia se debruçar para trazer movimento ao estado da paciente a fim de que ela pudesse reconstruir sua história.

A canção composta pela paciente com o apoio do musicoterapeuta na décima sétima sessão foi outro marco importante no processo musicoterapêutico uma vez que pontua uma mudança de atitude perante si mesma e perante as demais pessoas. A análise semiótica musicoterapêutica desta segunda canção permitiu ao musicoterapeuta compreender e descrever o estado da paciente naquele momento, trazendo uma importante constatação sobre a necessidade de utilizar a força da paciente, auxiliando-a a direcioná-la para a ação. Mas não qualquer ação, e, sim, as ações que lhe auxiliariam a encontrar caminhos mais frutíferos para sua jornada. A energização representada pelo gradual aumento da tensão na segunda parte da canção Hoje eu tô risonha foi utilizada posteriormente em diversos momentos do processo musicoterapêutico tanto por meio musical como físico, exercitando com a paciente o processo de planejamento e preparação para ação após a conscientização do estado atual, bem como dos desejos e das necessidades. A paciente também reconheceu que poderia ter um produto bem organizado e elaborado, com um resultado que fosse de seu agrado e isso, por sua vez, lhe mostrou que um esforço bem direcionado poderia ter resultados positivos, mesmo em meio a dificuldades ou entraves.

As duas canções, tanto quanto outras compostas e ou recriadas posteriormente, também podem configurar um portfólio de elementos musicais que reescrevem simbolicamente o percurso realizado ao longo do processo. Elas são marcos de momentos ou de fases do processo ao mesmo tempo em que permitem novas formas de compreensão e ação a partir daquele ponto. Enquanto a audição e a recriação da primeira canção permitiu à paciente dar-se conta de e expressar conteúdos que poderiam ser proibidos ou inacessíveis de outro modo, a composição da paciente com apoio do musicoterapeuta lhe favoreceu explorar e organizar ideias sobre si mesma, além de expressá-las com controle e de modo socialmente valorizado.

\section{Considerações finais}

As canções têm sido utilizadas de diversos modos por musicoterapeutas de todo mundo desde o início da prática científica da musicoterapia na primeira metade do século XX (BRUSCIA, 2000; MILLECO FILHO; BRANDÃO; MILLECCO, 2001; WIGRAM; PEDERSEN; BONDE, 2002).

Este artigo apresentou uma proposta de análise de canções no contexto musicoterapêutico construído a partir da teoria e prática da Semiótica da Canção por Luis Tatit e colaboradores. Foi também resumidamente descrido um caso clínico no qual a análise semiótica musicoterapêutica de duas canções foi utilizada. A análise destas canções serviu como avaliação musicoterapêutica daquela fase do processo musicoterapêutico, fornecendo 
ao terapeuta uma melhor compreensão do que estava ocorrendo no processo terapêutico, do caminho já percorrido até então e de quais intervenções poderiam ser implementadas a partir de então.

Contudo, cabe ressaltar, como já mencionado anteriormente, que este protocolo não pode ser instituído como um esquema fechado, de passos a serem estritamente seguidos. Pelo contrário, ele é um protocolo aberto, com sugestões de procedimentos que devem ser avaliados e implementados de acordo com a necessidade clínica e com o contexto específico de cada processo musicoterapêutico em que for utilizado. Por exemplo, em algumas análises (como as apresentadas neste artigo), pode-se focar mais na letra da canção, na música e na relação entre elas enquanto em outras, pode-se dar maior peso para os arranjos e modos de interpretação. A análise semiótica musicoterapêutica de canções pode ser uma ferramenta útil para compreender a etapa do processo musicoterapêutico que está sendo vivenciada e, também, para indicar possíveis caminhos futuros de intervenção clínica musicoterapêutica com o paciente. Consideramos ser possível trabalhar com canções na clínica musicoterapêutica com uma grande gama de populações clínicas de modo não reducionista ou limitado somente ao trabalho com a letra da canção. Pelo contrário, propomos considerar a experiência musical em toda a sua integridade, plenitude e potência para transformação.

\section{Notas}

1 No Brasil, costuma-se utilizar o termo "recriação" para a performance por meio de canto e/ou de instrumentos musicais de músicas previamente compostas (pelo paciente ou por outras pessoas). Conforme Barcellos (2016) e Bruscia (2000), neste momento, o paciente não somente "executa” uma música previamente existente, mas a "recria" pois lhe dá novo sentido a partir da execução no contexto da relação terapêutica naquele momento específico do processo terapêutico.

2 Semiótica, conforme Nöth (1995), é a ciência que estuda os signos e os processos de significação (semiose) tanto na natureza como na cultura.

3 Devido ao escopo deste artigo, não será descrito o pensamento clínico do musicoterapeuta para as escolhas e direcionamentos musicais ao longo do processo de composição da canção "Hoje eu tô risonha”. O percurso da composição desta canção será objeto de um artigo futuro.

\section{Referências}

AUSTIN, Diane S. Canções do Self: Canto Improvisado em Musicoterapia Analítica - Junguiana. In: BARCELLOS, L. R. M. (Ed.). Musicoterapia: Transferência, Contratransferência e Resistência. Rio de Janeiro: Enelivros, 1999. p.75-88.

AUSTIN, Diane S. Voice of Trauma: A Wounded Healer's Perspective. In: SUTTON, J. P. (Ed.). Music, Music Therapy and Trauma: International Perspectives. London: Jessica Kingsley, 2002. p. 231-259.

AUSTIN, Diane S.; DVORKIN, Janice M. Resistance in Individual Music Therapy. In: BRUSCIA, K. E. (Ed.). The Dynamics of Music Psychotherapy. Gilsum: Barcelona, 1998. p. 121-135.

BAKER, Felicity; TAMPLIN, Jeanette; KENNELLY, Jeanette. Music therapy methods in neurorehabilitation: a clinician’s manual. London: Jessica Kingsley, 2006. 256 p.

BARCELLOS, Lia Rejane M. A previsibilidade da canção popular como "holding" às mães de bebês prematuros. In: Congresso da Associação de Pesquisa e Pós-Graduação em Música, XV, 2005, Rio de Janeiro. Anais... Rio de Janeiro: Escola de Música - UFRJ, 2005. p. 1314-1322.

BARCELLOS, Lia Rejane M. Etapas do Processo Musicoterapêutico - ou para uma Metodologia de Musicoterapia. In: BARCELLOS, Lia Rejane M. Quaternos de Musicoterapia e Coda. Dallas: Barcelona, 2016. p. 187-244. 
BAXTER, Holly T. et al. The Individualized Music Therapy Assessment Profile: IMTAP. London: Jessica Kingsley, 2007. 192p.

BENENZON, Rolando O. Manual de Musicoterapia. Rio de Janeiro: Enelivros, 1985. 182p.

BOXILL, Edith H. Music Therapy for the Developmentally Disabled. Austin: Pro-ed, 1985. 270p.

BRANDALISE, André. Approach Brandalise de Musicoterapia (Carta de Canções). Revista Brasileira de Musicoterapia, Rio de Janeiro, v. 4, p. 41-55, 1998.

BRITO, Murilo. A Canção Desencadeante. Revista Brasileira de Musicoterapia, Rio de Janeiro, v. 5, p. 94-97, 2001.

BRUSCIA, Kenneth E. An Introduction to Music Psychoterapy. In: BRUSCIA, Kenneth E. The Dynamics of Music Psychotherapy. Gilsum: Barcelona, 1998. p. 1-15.

BRUSCIA, Kenneth E. Definindo Musicoterapia. Rio de Janeiro: Enelivros, 2000. 312p.

BRUSCIA, Kenneth E. Improvisational Models of Music Therapy. Springfield: C.C. Thomas, 1987. 585p.

CIRIGLIANO, Márcia M. S. A Canção Âncora: descrevendo e ilustrando a contratransferência em Musicoterapia. Revista Brasileira de Musicoterapia, Rio de Janeiro, v. 7, p. 38-42, 2004.

CIRIGLIANO, Márcia M. S. Pesquisa na Clínica Musicoterápica: a Canção como Âncora Terapêutica. Revista Brasileira de Musicoterapia, Rio de Janeiro, v. 4, p. 33-40, 1998.

COSTA, Clarice M. Musicoterapia para Deficiências Mentais. Lisboa: Clio, 1995. 127p.

COSTA, Clarice M. O Despertar para o Outro: Musicoterapia. São Paulo: Summus, 1989. 127p.

DIETRICH, Peter. Semiótica do Discurso Musical: uma discussão a partir das canções de Chico Buarque. 2008. 256f. Tese (Doutorado em área?) - Faculdade de Filosofia, Letras e Ciências Humanas da Universidade de São Paulo, São Paulo, 2008.

DILEO, C. (Ed.). Music Therapy and Medicine: Theoretical and Clinical Applications. Silver Spring, MD: American Music Therapy Association, 1999. 211p.

DILEO, Cheryl; MAGILL, Lucanne. Songwriting with Oncology and Hospice Adult Patients forma a Multicultural Perspective. In: BAKER, Felicity; WIGRAM, Tony (Ed.). Songwriting: Methods, Techniques and Clinical Applications for Music Therapy Clinicians, Educators and Students. London: Jessica Kingsley, 2005. p. 226-245.

GATTINO, Gustavo S. et al. Tradução, adaptação transcultural e evidências de validade da escala Improvisation Assessment Profiles (IAPs) para uso no brasil: parte 2. Revista Brasileira de Musicoterapia, Curitiba, v. 21, p. 51-72, 2016.

HANSER, Suzanne B. The New Music Therapist's Handbook. $2^{\text {nd }}$ ed. Boston: Berklee, 1999. 256p.

KIRKLAND, Kevin H. (Ed.). International Dictionary of Music Therapy. New York: Routledge, 2013. 224p.

MACHADO, Regina. Da intenção ao gesto interpretativo: análise semiótica do canto popular brasileiro. 2012. 192f. Tese (Doutorado) - Faculdade de Filosofia, Letras e Ciências Humanas da Universidade de São Paulo, São Paulo, 2012.

MILLECCO, Ronaldo. Ruídos da Massificação na Construção da Identidade Sonora-Cultural. Revista Brasileira de Musicoterapia, Rio de Janeiro, v. 3, p. 5-15, 1997.

MILlECO FILHO, Luiz Antônio; BRANDÃO, Maria Regina; MILlECCO, Ronaldo. É Preciso Cantar: Musicoterapia, Cantos e Canções. Rio de Janeiro: Enelivros, 2001. 120 p. 
NORDOFF, Paul; ROBBINS, Clive; MARCUS, David. Creative Music Therapy: a guide to fostering clinical musicianship. Gilsum: Barcelona, 2007. 516 p.

NÖTH, Winfried. A semiótica no século XX. São Paulo: Annablume, 1996. 314p.

NÖTH, Winfried. Panorama da Semiótica de Platão a Peirce. São Paulo: Annablume, 1995. 150 p.

OLDFIELD, Amelia. Interactive music therapy in child and family psychiatry: clinical practice, research, and teaching. London: Jessica Kingsley, 2006. 224 p.

OLDFIELD, Amelia; FRANKE, Christine. Improvised Songs and Stories in Music Therapy Diagnostic Assessments at a Unit for Child and Family Psychiatry: A Music Therapist's and a Psychoterapist's Perspective. In: BAKER, Felicity; WIGRAM, Tony (Ed.). Songwriting: Methods, Techniques and Clinical Applications for Music Therapy Clinicians, Educators and Students. London: Jessica Kingsley, 2005. p. 24-44.

PERETZ, Isabelle. The nature of music from a biological perspective. Cognition, v. 100, n. 1, p. 1-32, 2006. DOI: 10.1016/j.cognition.2005.11.004

PERETZ, Isabelle; CHAMPOD, Anne Sophie.; HYDE, Krysta. Varieties of musical disorders. The Montreal Battery of Evaluation of Amusia. Annals of the New York Academy of Sciences, v. 999, p. 58-75, 2003.

PODLIPNIAK, Piotr. The Role of the Baldwin Effect in the Evolution of Human Musicality. Frontiers in Neuroscience, v. 11, p. 1-12, 2017. DOI: 10.3389/fnins.2017.00542

RUUD, Even. Soundtracks of our life. In: BAKER, Felicity; WIGRAM, Tony (Ed.). Songwriting: Methods, Techniques and Clinical Applications for Music Therapy Clinicians, Educators and Students. London: Jessica Kingsley Publishers, 2005. p. 9-10.

SAMPAIO, Ana Cristina; SAMPAIO, Renato Tocantins. Da escuta à Intervenção. In: SAMPAIO, Ana Cristina; SAMPAIO, Renato Tocantins. Apontamentos em Musicoterapia. São Paulo: Apontamentos, 2005. v. 1. p. 9-12.

SAMPAIO, Renato Tocantins. A Canção na Musicoterapia - uma visão humanista. In: ENCONTRO MINEIRO DE MUSICOTERAPIA, 21., 2010, Belo Horizonte. (Manuscrito não publicado). $8 \mathrm{p}$.

SAMPAIO, Renato Tocantins. Avaliação da Sincronia Rítmica em crianças com Transtorno do Espectro do Autismo em Atendimento Musicoterapêutico. 2015. 138f. Tese (Doutorado) - Instituto de Ciências Biológicas da Universidade Federal de Minas Gerais, Belo Horizonte, 2015.

SAMPAIO, Renato T. Considerações sobre a Linguagem na Prática Clínica Musicoterapêutica numa Abordagem Gestáltica. In: Congresso da Associação de Pesquisa e Pós-Graduação em Música, XVII, 2007, São Paulo, Anais... São Paulo: Instituto de Artes (UNESP), 2007. p. 1-7.

SAMPAIO, Renato T. Novas Perspectivas de Comunicação em Musicoterapia. 2002. 85f. Dissertação (Mestrado) - Pontifícia Universidade Católica de São Paulo, São Paulo, 2002.

SCHAPIRA, Diego et al. Musicoterapia: abordaje plurimodal. Argentina: ADIM, 2007. 222p.

SHOEMARK, Helen. Singing as the Foundation for Multi-Modal Stimulation of the Older Preterm Infant. In: PRATT, Rosalie R.; GROCKE, Denise E. (Ed.). Music Medicine 3: Music Medicine and Music Therapy - Expanding Horizons. Parkville: University of Melbourne, 1999. p. 140-152.

SHOEMARK, Helen. The fundamental interaction of singing. Nordic Journal of Music Therapy, v. 23, n. 1, p. 2-4, 2014. DOI: 10.1080/08098131.2014.876178 
SILVA, Kristof. Contribuições do arranjo para a construção de sentido na canção brasileira: análise de três canções de Milton Nascimento. 2011. 136 f. Dissertação (Mestrado) - Escola de Música da Universidade Federal de Minas Gerais, Belo Horizonte, 2011.

TATIT, Luiz. A Canção: Eficácia e Encanto. São Paulo: Atual, 1986. 68p.

TATIT, Luiz. Análise semiótica através das letras. São Paulo: Ateliê Editorial, 2001. 208p.

TATIT, Luiz. Musicando a semiótica: ensaios. São Paulo: Annablume, 1997. 163p.

TATIT, Luiz. O cancionista: composição de canções no Brasil. São Paulo: Edusp, 1996. 328p.

TATIT, Luiz. Semiótica da canção: melodia e letra. São Paulo: Escuta, 1994. 254p.

TATIT, Luiz.; LOPES, Ivã Carlos. Elos de melodia e letra: análise semiótica de seis canções. São Paulo: Ateliê Editorial, 2008. 184p.

THAUT, Michael; HOEMBERG, Volker. (Ed.). Handbook of neurologic music therapy. New York: Oxford University Press, 2014. 384p.

VUVAN, Dominique T. et al. The Montreal Protocol for Identification of Amusia. Behavior Research Methods, v. 50, n. 2, p. 1-11, 2017. DOI: 10.3758/s13428-017-0892-8

WIGRAM, Tony; PEDERSEN, Inge N.; BONDE, Lars Ole. A Comprehensive Guide to Music Therapy: Theory, Clinical Practice, Research, and Training. London: Jessica Kingsley, 2002. 384p.

Fonte: Autor, ano.

Renato Tocantins Sampaio: Doutor em Neurociências (UFMG), Mestre em Comunicação e Semiótica (PUC-SP), Graduado em Musicoterapia (Fac. Marcelo Tupinambá) e em Educação Artística com Habilitação em Música (Fac. de Artes Santa Marcelina). Como musicoterapeuta clínico, possui experiência nas áreas de Distúrbios do Neurodesenvolvimento, Saúde Mental, Social e Hospitalar. Publicou diversos artigos, livros e capítulos de livros sobre Musicoterapia e sobre Educação Musical e ministrou palestras, cursos e conferências no Brasil e no exterior. Desde 2010, é Professor de Musicoterapia na Universidade Federal de Minas Gerais, onde atua na Graduação em Música, nas Especializações em Neurociências e em Transtorno do Espectro do Autismo, e nos Programas de Pós-Graduação Stricto Sensu em Música e em Neurociências. 